\title{
Pulmonary Adenofibroma: Report of a Rare Case with Amyloid Deposit
}

\author{
Emna Braham ${ }^{1^{*}}$, Imen Helal ${ }^{1}$, Mouna Mlika ${ }^{1}$, Tarek Kilani ${ }^{2}$ and Faouzi El Mezni ${ }^{1}$ \\ ${ }^{1}$ Department of Pathology, Abderrahman Mami Hospital, Ariana, Tunisia \\ ${ }^{2}$ Department of Thoracic Surgery, Abderrahman Mami Hospital, Ariana, Tunisia \\ *Corresponding author: Emna Braham, Department of Pathology, Abderrahman Mami Hospital, 2080 Ariana, Tunisia, Tel: 0021624822474; E-mail: \\ emnabraham@yahoo.fr
}

Rec date: Nov 15, 2014, Acc date: Dec 17, 2014, Pub date: Dec 19, 2014

Copyright: (C) 2014 Braham E, et al. This is an open-access article distributed under the terms of the Creative Commons Attribution License, which permits unrestricted use, distribution, and reproduction in any medium, provided the original author and source are credited.

\begin{abstract}
We report a case of a primary lung tumor characterized by complex gland-like spaces lined by simple cuboidal to columnar epithelium surrounded by a hyalinized spindle-cell fibroblastic proliferation reminiscent of adenofibroma of the female genital tract. The lesion occurred in a 56 year-old male with a history of left thoracic pain and hemoptysis. The tumor presented clinically as $1.5 \mathrm{~cm}$ solitary lesion and was discovered on chest X-rays. The lesion was treated by lobectomy. The main importance lies in distinguishing this lesion histologically from other types of pulmonary hamartoma, pulmonary blastoma, intrapulmonary solitary fibrous tumor and metastases from soft tissues and visceral sarcomas.
\end{abstract}

Keywords: Adenofibroma; Lung; Histology

\section{Introduction}

Pulmonary adenofibroma is a rare soft-tissue tumor with a glandular or epithelial component and a fibromatous stromal component, both of which are histologically benign. We report an exceptional case of pulmonary adenofibroma.

\section{Case Report}

A 56 year-old man, presented with a history of left chest pain and hemoptysis since 8 months. The computed tomography showed a homogenous, well defined nodule measuring $1.8 \times 1.3 \mathrm{~cm}$ in left lower lobe with an intense enhancement of the lesion. Fibreoptic bronchoscopy was performed with bronchial washings and bronchial biopsies. Cytology of washings and pathological examination of bronchial biopsies did not reveal malignancy, infection or vascularitis, only slight aspecific inflammation was noticed. These results were regarded non diagnostic. Detailed clinical and radiological evaluation failed to disclose tumor elsewhere.

Based on these imaging findings, the diagnosis of benign lesion was suspected. So we decided to undergo a resection of the lesion by thoracotomy. A wedge resection of the left lower lobe was performed. A frozen section was done in this lesion and confirmed the benignity. Macroscopically, the nodule was well defined, white-grey measuring $1.5 \mathrm{~cm}$. Histologically, the lesion was characterized by complex, branching spaces lined by a single layer of simple cuboidal to columnar epithelium surrounded by a densely sclerotic hyalinized stroma containing scattered spindle cells (Figure 1). The stromal component appeared to project into the lumen of the epithelium-lined spaces forming club-shaped papillary structures. In the stroma, we also noticed the presence of amyloid deposits with apple-green birefringence when stained with congo red and seen under polarized light (Figure 2). Immunohistochemically, the epithelial cells were positive for EMA and TTF-1 while the fibrous stroma was positive for vimentin and CD34. So a final diagnosis of pulmonary adenofibroma with amyloid deposits was made. The patient was in good health when last seen, 9 months after surgery (Table 1).

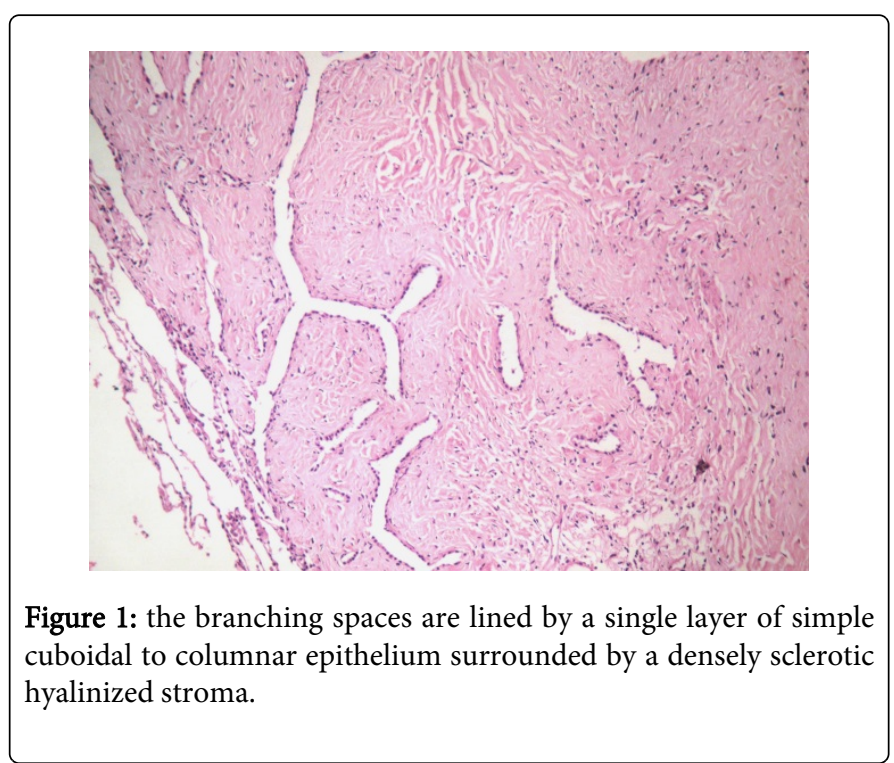

\section{Discussion}

Pulmonary adenofibroma was first reported by Scarff and Gowar in 1944 [1], since then, very few cases were reported. The histogenesis of this rare tumor remains a subject of debate. Scarff and Gowar [1] contended that it probably belong to the same family as chondroma of the lung. However, Butler and kleinerman [2], based on the presence of immature cartilage in their lesions, proposed that they were neoplastic rather than developmental. Stone and Churg [3], on the other hand, observed that many of the epithelial lining cells in these tumors resembled those encountered in fetal or developing lung, suggesting that the tumor might be a mixed neoplasm arising from epithelial and mesenchymal elements. Finally, Suster and Moran [4] examined the clinicopathological and immunohistochemical features 
Page 2 of 3

of two pulmonary adenofibromas and concluded that these tumors may represent an immature form of pulmonary hamartoma. This is supported by the fact that the core of the lesion is composed of uncommitted fibroblastic mesenchymal elements which have not attained the capability to differentiate into more specialized, mature elements such as cartilage, smooth muscle or fat.

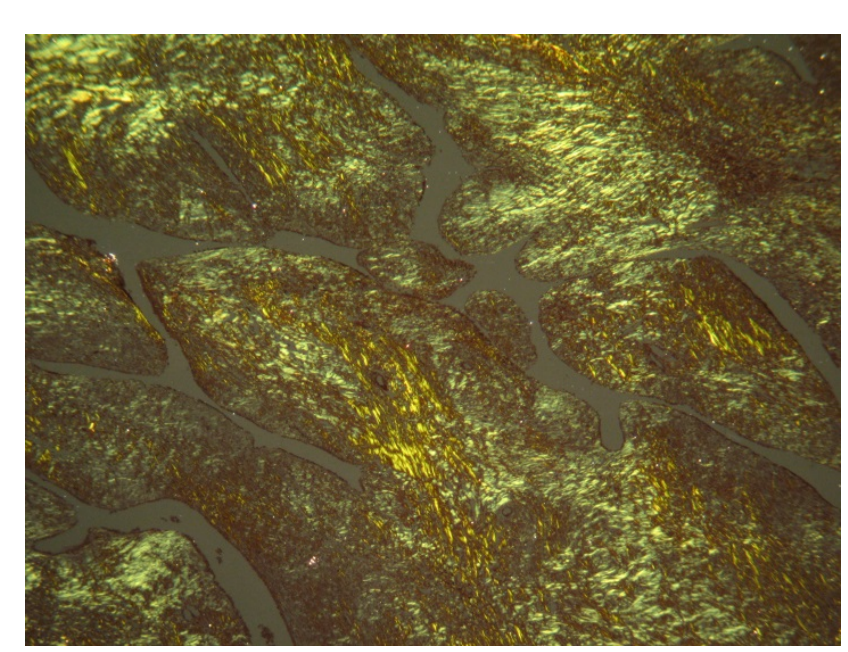

Figure 2: amyloid deposits with apple-green birefringence when stained with congo red and seen under polarized light.
We reviewed nine previous reported cases [1-8] and the present case. The average age at presentation of patients with pulmonary adenofibroma is 49.8 years (29-66 years) with male preponderance (sex ratio=6:4). The symptoms were essentially chest pain (4 cases), cough (1 case) and hemoptysis (1 case). The lesion was asymptomatic in 4 cases.

The computed tomography showed a well circumscribed nodule in 8 cases (Table 1). A solid cystic lesion was seen in one case [8]. The lesion was located in the left lung in 7 cases and in the right lung in 2 cases in. Five cases of pulmonary adenofibromas from 7 were located in close proximity to the pleural surface.

The treatment consisted in lobectomy in 5 cases. A resection of the lesion was done in 3 cases. The treatment was not precise in the other cases.

Macroscopically, the size of the tumor varies from 0.8 to $2 \mathrm{~cm}$ with average of $1.36 \mathrm{~cm}$. Histologically, the lesion was characterized by complex, branching spaces lined by a single layer of simple cuboidal to columnar epithelium surrounded by a densely sclerotic stroma containing scattered spindle cells. The stromal component appeared to project into the lumen of the epithelium-lined spaces forming clubshaped papillary structures. Amyloid deposits were seen only in our case.

Immunohistochemically, the epithelial cells were positive for EMA and TTF- 1 while the fibrous stroma was positive for vimentin and CD34. Immunohistochemical stains were done and were positive in three cases $[4,5]$.

\begin{tabular}{|c|c|c|c|c|c|}
\hline Author/year & Age/Sex & Symptoms & Computed Tomography & Treatment & Evolution \\
\hline Scarff and Gowar [1] & 66/Male & No symptoms & $\begin{array}{l}1 \mathrm{~cm} \text { nodule in the left upper } \\
\text { lobe }\end{array}$ & NA & NA \\
\hline Suster and Moran [4] & 54/Female & No symptoms & $\begin{array}{l}1 \mathrm{~cm} \text { lesion in the right upper } \\
\text { lobe }\end{array}$ & Lobectomy & $\begin{array}{l}\text { Well } 8 \text { years after } \\
\text { surgery }\end{array}$ \\
\hline Suster and Moran [4] & 56/Male & No symptoms & $\begin{array}{l}2 \mathrm{~cm} \text { lesion in the left upper } \\
\text { lobe }\end{array}$ & Lobectomy & $\begin{array}{l}\text { Died } 5 \text { years later } \\
\text { (acute myocardial } \\
\text { infarction) }\end{array}$ \\
\hline Cavazza [2] & 62/Male & No symptoms & $\begin{array}{l}0.8 \mathrm{~cm} \text { nodule in the lower lobe } \\
\text { of right lung }\end{array}$ & Surgical resection & $\begin{array}{l}\text { Well } 18 \text { months after } \\
\text { excision }\end{array}$ \\
\hline Wang [5] & 55/Male & Chest pain & $\begin{array}{l}\text { Homogenous } 2 \mathrm{~cm} \text { nodule in } \\
\text { the lower lobe of the left lung }\end{array}$ & $\begin{array}{l}\text { Complete surgical } \\
\text { resection }\end{array}$ & $\begin{array}{l}\text { In good health } 16 \\
\text { months after surgery }\end{array}$ \\
\hline Vitkovski [6] & 29/Female & Chest pain & NA & NA & NA \\
\hline Rajiv Kumar [8] & 25/Male & Cough+hemoptysis & $\begin{array}{l}\text { Solid cystic lesion in left upper } \\
\text { lobe }\end{array}$ & Lobectomy & No recurrence \\
\hline Rajiv Kumar [8] & 40/Female & Chest pain+ dyspnea & $\begin{array}{l}\text { Subpleural homogenous } \\
\text { nodule in left lower lobe }\end{array}$ & Lobectomy & No recurrence \\
\hline Rajiv Kumar [8] & 55/female & Chest pain+ dyspnea & $\begin{array}{l}\text { Subpleural homogenous } \\
\text { nodule in left lower lobe }\end{array}$ & Lobectomy & No recurrence \\
\hline Our case & $56 /$ male & Chest pain+hemoptysis & $\begin{array}{l}\text { Homogenous, well defined } \\
\text { nodule in left lower lobe }\end{array}$ & Wedge resection & $\begin{array}{l}\text { No recurrence after } \\
4 \text { months }\end{array}$ \\
\hline
\end{tabular}

Table 1: Clinical and pathological findings of reported cases of pulmonary adenofibroma 
Page 3 of 3

Because of the absence of mature elements such as cartilage, fat or smooth muscle, these lesions must be distinguished from other primary and metastatic lung tumors which carry a more ominous prognosis. Pulmonary blastoma, although sharing the biphasic epithelial/spindle cell composition, are characterized by the more primitive appearance of the glandular elements, and which resemble that of respiratory epithelium during the weeks 8-10 of gestation [4].

Additionally, pulmonary blastomas tend to be large, destructive tumors with areas of hemorrhage and necrosis and marked cytological atypia of the spindle cell component. Carcinosarcoma of the lung is another biphasic neoplasm that may enter the differential diagnosis: these tumors, however, are highly aggressive malignant neoplasms that will generally attain a large size and display obvious features of malignancy. An important consideration in the differential diagnosis is the rare occurrence of an intrapulmonary solitary fibrous tumour (localized fibrous mesothelioma). Such tumors are characterized by a spindle cell proliferation which may frequently entrap normal respiratory epithelium at their periphery. Because such tumors reproduce a variety of histological growth patterns in their spindle cell component, they may be mistaken for different types of malignant mesenchymal neoplasms [4].

A clue to the diagnosis lies in the diffuse distribution and complex arrangement of the glandular epithelial elements in pulmonary adenofibroma, as opposed to the peripheral location and haphazard arrangement of the entrapped respiratory epithelium in solitary fibrous tumors [4].

A final consideration in the differential diagnosis of these lesions is their distinction from metastatic sarcomas to the lung. Metastases of sarcomas to the lung may often infiltrate adjacent pulmonary parenchyma by displacing and entrapping normal air spaces at the periphery of the lesions thereby simulating the appearance of a biphasic epithelial/stromal neoplasm. Moreover, the spindle stromal component in some of those lesions, such as in benign metastasizing leiomyoma and uterine stromal sarcoma, may be devoid of atypia and mitotic activity [4].
Finally, the clinical behavior of the lesion was generally that of a benign neoplasm but adenofibroma could potentially undergo malignant transformation and metastasize to other organs [5]. Seven patients were in good health with no recurrence. One patient died five years after surgery because of an acute myocardial infarction.

\section{Conclusion}

We believe the lesions here described are best interpreted as a variant of pulmonary hamartoma with a prominent fibroblastic stromal component. Attention to the histological and immunohistochemical features will help avoid confusing them for other tumours with a more aggressive biological potential.

\section{References}

1. Scarff RW, Gowar FJS (1944) Fibroadenoma of the lung. J Pathol Bacteriol 56: 257-258.

2. Butler C, Kleinerman J (1969) Pulmonary hamartoma. Arch Pathol 88: 584-592.

3. Stone F, Churg A (1977) The ultrastructure of pulmonary hamartoma. Cancer 39: 1064-1070.

4. Suster S, Moran CA (1993) Pulmonary adenofibroma: report of two cases of an unusual type of hamartomatous lesion of the lung. Histopathology 23: 547-551.

5. Wang Y, Xiao HL, Jia Y, Chen JH, He Y, et al. (2013) Pulmonary adenofibroma in a middle-aged man: report of a case. Surg Today 43: 690-693.

6. Vitkovski T, Zeltsman D, Esposito M, Morgenstern N (2013) Pulmonary adenofibroma: cytologic and clinicopathologic features of a rare benign primary lung lesion. Diagn Cytopathol 41: 991-996.

7. Sironi M, Rho B, Spinelli M (2005) Adenofibromatous pattern in a solitary fibrous tumor of the lung. Int J Surg Pathol 13: 79.

8. Rajiv Kumar, Saral Desai, Trupti Pai, Pramesh CS, Nirmala Ajit Jambheka (2014) Pulmonary adenofibroma. Clinicopathological study of three cases of a rare benign lung lesion and review of the literature. Annals of Diagnostic Pathology. Ann Diagn Pathol 18: 238- 243. 